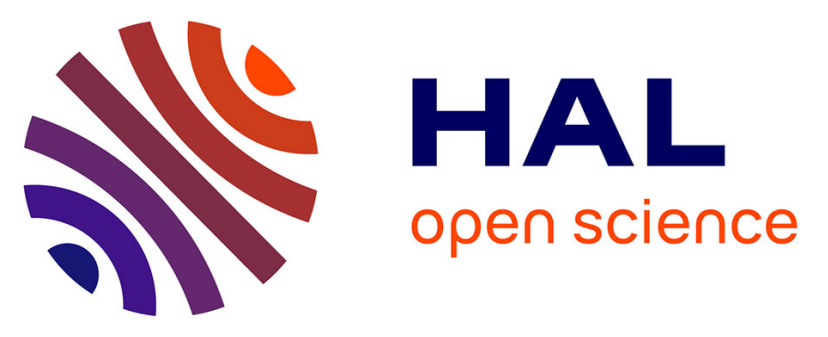

\title{
Twin vaginal delivery: To maintain skill - simulation is required
}

\author{
Julien Lepage, Pierre Francois Ceccaldi, Sid Ahmed Remini, Patrick \\ Plaisance, Audrey Voulgaropoulos, Dominique Luton
}

\section{To cite this version:}

Julien Lepage, Pierre Francois Ceccaldi, Sid Ahmed Remini, Patrick Plaisance, Audrey Voulgaropoulos, et al.. Twin vaginal delivery: To maintain skill - simulation is required. European Journal of Obstetrics \& Gynecology and Reproductive Biology, 2019, 234, pp.195 - 199. 10.1016/j.ejogrb.2018.12.038 . hal-03486879

\section{HAL Id: hal-03486879 \\ https://hal.science/hal-03486879}

Submitted on 20 Dec 2021

HAL is a multi-disciplinary open access archive for the deposit and dissemination of scientific research documents, whether they are published or not. The documents may come from teaching and research institutions in France or abroad, or from public or private research centers.
L'archive ouverte pluridisciplinaire HAL, est destinée au dépôt et à la diffusion de documents scientifiques de niveau recherche, publiés ou non, émanant des établissements d'enseignement et de recherche français ou étrangers, des laboratoires publics ou privés.

\section{다)(1) $(5$}

Distributed under a Creative Commons Attribution - NonCommerciall 4.0 International 


\section{Twin vaginal delivery; to maintain skill - simulation is required.}

Julien LEPAGE ${ }^{1,2} \mathrm{MD}$, Pierre Francois CECCALDI ${ }^{2,3,4,5} \mathrm{MD}, \mathrm{PhD}$, Sid Ahmed REMINI ${ }^{4} \mathrm{Mr}$, Patrick PLAISANCE ${ }^{2,4,6}$ MD,PhD , Audrey VOULGAROPOULOS ${ }^{1}$ MD, Dominique LUTON $^{1,2,4,5}$ $\mathrm{MD}, \mathrm{PhD}$.

1-Hôpital Bichat, Maternité Aline de Crepy. APHP 75018 Paris, France

2-Université Paris Diderot, Paris 7, Paris, France

3-Hôpital Beaujon, Service de gynécologie obstétrique, APHP 92110 Clichy, France

4-llumens Paris Diderot, centre de simulation, Paris, France

5-DHU Risk and Pregnancy (Paris V and Paris VII University) France

6-Hôpital Lariboisière , Emergency Unit, APHP 75018 Paris, France

\section{Corresponding Author:}

Dominique LUTON MD,PhD; Hôpital Bichat, Maternité Aline de Crepy APHP . 46 rue Henry Huchard 75018 Paris, France. Phone +33140257673 Cell Phone +33618182756. Mail : dluton@free.fr or dominique.luton@aphp.fr

Potential conflicts of interest: The authors report no conflict of interest

\section{Funding}

None

Word count:

Abstract: 158

Main text: 1736 


\section{Condensation:}

There is a need for promoting and teach vaginal twin delivery. We have therefore designed a realistic simulation model with positive results when applied to obstetrics residents.

Short Title:

Simulation for vaginal twin delivery

\section{AJOG at a Glance}

A. Why was this study conducted?

There is a serious and urgent need to reintroduce vaginal delivery for twins. Simulation for residents and practitioners is an interesting and well accepted educational tool.

\section{B. What are the key findings?}

A realistic simulation device for second twin delivery has been built and is efficient. We show here its interest in improving residents skills for second twin vaginal delivery.

\section{What does this study add to what is already known ?}

This study add another proof for the place of simulation in our pedagogic tools, and show a simulation model responding to urgent need in obstetrical practice.

Key words Twin Delivery, Vaginal delivery, internal version, simulation 
ABSTRACT

Background: Although most societies of obstetrics advocate vaginal delivery of twins, there has been a steady rise in the rate of twin cesarean sections. We risk perhaps losing in a single generation our obstetrical learning and skills because of medicolegal and emotionally charged issues.

Methods:

We have therefore designed a realistic as possible simulation model of second twin delivery and tested it on residents in obstetrics.

\section{Findings}

Between two trials, we noted a significant improvement in the time required for internal podalic version and breech extraction. We also observed a significant improvement in the confidence score between the two trials.

\section{Interpretation}

We have designed a simulation device that improves obstetrical skills for second twin delivery and which we hope will participate in the comeback of vaginal delivery for this indication and contribute to the fight against the dangerous trend of rising rates of cesarean delivery for twins. Our model completely fits the paradigm of simulation in medical pedagogy. 


\section{Introduction}

Twin delivery has always been a matter of discussion among perinatologists. The first revolution in the 1990s was the notion that active management of second twin delivery was preferable to delayed delivery, which resulted in worse perinatal outcome (1-3). Meanwhile, medicolegal and social considerations resulted in a dramatic rise in C-section rate (4) and also a loss of obstetrical skills leaving the next generation with caesarean delivery as its sole tool, and even the inability to perform emergency procedures faster than cesarean delivery. In parallel, we now have to face all the complications of undue uterine scars (5). American consensus guidelines as well as French guidelines recently promoted vaginal delivery of twin pregnancies $(6,7)$. According to these guidelines, second twin delivery should be actively managed and this depends largely on knowledge of specific obstetrical maneuvers. Training residents in these maneuvers remains a difficult priority and even leads some authors to speak of "innovate or abdicate". A parallel goal is to train obstetricians to maintain their skills and teach them to future generations of clinicians. Change in experience may require use of innovative strategies to help improve residents' basic obstetric skills (8).

The most recent analysis of trends in twin delivery demonstrates rising rates of cesarean delivery (as high as 75\% in 2008), regardless of the second twin's presentation (4). Nevertheless, the Jumeaux Mode d'Accouchement study of a large prospective cohort in France concluded that noncephalic and cephalic second twin presentations after vaginal delivery of the first twin above 32 weeks of gestation are associated with similar low composite neonatal mortality and morbidity (9), therefore these authors advocate vaginal delivery "as long as the obstetrical skillsets remain available". Thus, this increase in cesarean 
rates in twins, despite recommendations to practice vaginal birth, which involves fewer maternal and fetal risks, is due to a lack of obstetricians trained in these maneuvers and who choose the supposed ease of C-sections.

We postulate that young obstetricians should be trained in twin vaginal birth that includes internal podalic version and breech extraction for the delivery of an unengaged (cephalic or not) second twin. Nowadays, unfortunately, skills acquisition at the patient's bedside is difficult and even almost unimaginable in the early stages of learning. The admonition "Never the first time on the patient" written in gold letters at the entrance of the Center for Medical Simulation (CMS) in Boston (MA, USA) acquires its full force in this setting (10). And

it is in this context that simulation finds its value (11). Interestingly, most practicing obstetricians interviewed for a study identified simulator-based training as the preferred mode of training (12). Simulation plays a key role in medical education for training regarding low-frequency high-acuity events in obstetrics. There is renewed interest in the use of simulation for operative obstetrics (13) and we therefore present our device for second twin delivery simulation and its evaluation.

\section{Materials and Methods}

Our University (Paris VII Denis Diderot) has recently developed a simulation center (Ilumens Paris Diderot) dedicated to the teaching of all types of healthcare courses and to developing both technological and cross-functional procedures. In this context, we set up some second twin vaginal delivery training sessions for residents in obstetrics. The purpose of these sessions was to design a valuable model for extraction of the second twin and to test the 
hypothesis that we would see an improvement between two sessions in the skills of medical students regarding internal podalic version and breech extraction.

We evaluated 10 obstetrics residents at the llumens Simulation center in two sessions separated by one month. We used the simulator SimMom (LaerdalC) (Figure 1). This simulator is a realistic human-sized mannequin that allows for multiple medical procedures including instrumental fetal extraction and obstetrical maneuvers. We modeled an amniotic sac very simply with the help of a thin and transparent plastic trash bag filled with water at $37^{\circ} \mathrm{C}$. A fetus model representing a twin of about 2500 grams was placed in the bag, which was simply closed by a knot while carefully removing the air (Figure 2 ). The whole amniotic cavity with the fetus was placed in the abdominal structure of the SimMom model whose volume represented a gravid uterus. The fetus was placed by the teacher-trainer in an unengaged cephalic presentation with its back to the left or right of the patient (Figure 3). The student was not aware of the exact presentation.

Maneuvers were also evaluated with the Gaumard manikin@, which is also a possibility for such simulations (results with this model are not presented in this study). The sessions were divided into three parts: briefing, simulation exercise and debriefing.

Before the maneuver, each student was briefed about the procedure for second twin delivery, which was based principally on what we developed previously on an interactive CDROM based on obstetric techniques focused on the management of twin pregnancies, including three-dimensional models and interactive sequences (Obstetric techniques for twin pregnancies, Guigoz Laboratories, Marne-la-Vallée, France). Particular attention was paid to the means of identifying the fetus's foot and the technique of rotation. Before the 
procedure, the student was also asked to concentrate and to try and act as if he/she was in a real clinical situation.

We evaluated in the 2 sessions each student's performance in the obstetric maneuvers and his/her feelings. The obstetric maneuvers were evaluated from when the student's hand entered the patient's vulva to when the fetal foot exited the vulva (Figure 4), but also to when the fetal head was brought to the vulva. This covered, therefore the time needed to complete internal podalic version and breech extraction (Movie 1). The internal view of the procedure was also done (Figure 5). Time needed to complete delivery was chosen as a judgment criteria because its reflects somehow an ease in the procedure but also because it has been shown a continuous $\mathrm{pH}$ decline in the cord blood of the second twin as time to delivery increases (14).

During the debriefing of the session, each student's feelings were evaluated using a confidence score for the performance of the maneuvers and an anxiety score, respectively from 0 to 10 and from 0 to 5 . We also asked the student to rate the reality (0-10) of the procedure and for those who had already performed the procedure in real life to say to what extent the procedure simulated reality.

\section{Results}

Comparison of the two sessions showed an improvement in the time needed for internal podalic version and breech extraction of the second twin. The time to bring the fetal foot to the vulva was significantly reduced in the second session. However, we did not find any significant difference (despite a trend) in the duration of complete delivery, but the whole 
procedure including breech may be not as realistic as the descent of the foot to the vulva. The anxiety score did not vary significantly between the two sessions, whereas the confidence score improved. The realism of the device itself was deemed satisfactory (Tables 1 and 2).

\section{Comment}

Following the recommendations for continued training by simulation (15), the establishment of simulation centers seems mandatory. The aim of the simulation procedure is to improve knowledge, technical skills and interprofessional communication. With simulators, there is no risk to patients; the practice is standardized, regular and repeated for rare or occasional obstetric situations such as internal podalic version and breech extraction of the second twin. One of the main points is that no patient has to pay the tribute of being a junior doctor's first experience, which is especially important in obstetrics where numerous medicolegal, social and emotional factors have to be considered. Simulation programs in obstetrics have already been tested for shoulder dystocia (16-19)_ and breech delivery (20). For example, for shoulder dystocia, trained residents had significantly higher scores including timelines of their interventions, performance of maneuvers, and overall performance. They also performed the delivery in a shorter time than control subjects (61 versus 146 seconds, $P=.003$ (19). On the other hand, for breech delivery, trained residents showed significantly higher performance in the delivery and safety during the delivery also improved significantly ( $P=.001$ for both) (20).

Strong programs include didactic briefing, simulation, and debriefing sessions. The didactic briefing helps ensure that participants have baseline knowledge about the subject matter. The simulation allows attendees to have practical hands-on experience. The debriefing 
allows attendees to evaluate their own performance and to discuss system issues that impair optimal outcomes.

Recently, Birsner (21) developed a device for internal version, but the description was far less realistic and no evaluation has been furnished. But it was the first device allowing the tactile sensation of fetal part identification of a floating fetus and the grasping of the fetus through an amniotic sac.

In our experience, we have set up a simulator that is simple to implement. We have demonstrated that these simulation sessions are useful for learning and perfecting obstetric maneuvers. We believe that simulation learning could maintain "the art" of obstetrics and thus limit the increasing number of cesareans, not all of which are justified.

It is interesting to note in the results of this study that despite greater self-confidence in performing this obstetric maneuver, the feeling of anxiety is constant. We can therefore translate these results into the future reality of these students who will be anxious facing this clinical situation because each case is different, but confident in their ability to achieve a successful delivery. Indeed, there is no simulation without evaluation. The Kirkpatrick model has four levels of learning evaluation. Level 1 is the reaction just after the simulation session during the debriefing; level 2 is the technical skills learned during the session; level 3 is the ability to use what has been learned during the simulation session on patients; and level 4 is the evaluation of the impact of simulation on patient health (22). We believe that our simulations sessions allow students to reach level 2 , and that further studies are needed to evaluate the sessions at levels 3 and 4.

We have presented here a simulation model of internal podalic version and breech extraction of the second twin. This model is easy to implement and we demonstrate its effectiveness in the skills acquisition of young obstetric residents. It simulates a fetus 
floating in an amniotic cavity which allows the learner to perform the maneuver with realistic tactile sensations. Our model fits completely with the paradigm of simulation in medical pedagogy. 


\section{References}

1. Sibony O, Touitou S, Luton D, Oury JF, Blot PH. A comparison of the neonatal morbidity of second twins to that of a low-risk population. Eur J Obstet Gynecol Reprod Biol. 2003 Jun 10;108(2):157-63.

2. Pons J-C, Dommergues $M$, Ayoubi J-M, Gélébart $M$, Papiernik E. Delivery of the second twin: comparison of two approaches. Eur J Obstet Gynecol Reprod Biol. 2002 Aug $5 ; 104(1): 32-9$.

3. Schmitz T, Carnavalet C de C, Azria E, Lopez E, Cabrol D, Goffinet F. Neonatal outcomes of twin pregnancy according to the planned mode of delivery. Obstet Gynecol. 2008 Mar;111(3):695-703.

4. Lee HC, Gould JB, Boscardin WJ, El-Sayed YY, Blumenfeld YJ. Trends in cesarean delivery for twin births in the United States: 1995-2008. Obstet Gynecol. 2011 Nov;118(5):1095101.

5. d'Ercole C, Sentilhes L, Vayssière C, Rozenberg P. [Delivery in women with previous cesarean section or other uterine surgery: guidelines for clinical practice - introduction]. J Gynecol Obstet Biol Reprod (Paris). 2012 Dec;41(8):692-4.

6. American College of Obstetricians and Gynecologists, Society for Maternal-Fetal Medicine. ACOG Practice Bulletin No. 144: Multifetal gestations: twin, triplet, and higher-order multifetal pregnancies. Obstet Gynecol. 2014 May;123(5):1118-32. 
7. Schmitz T. [Management of second twin delivery]. J Gynecol Obstet Biol Reprod (Paris). 2009 Dec;38(8 Suppl):S114-21.

8. Gupta N, Dragovic K, Trester R, Blankstein J. The Changing Scenario of Obstetrics and Gynecology Residency Training. J Grad Med Educ. 2015 Sep;7(3):401-6.

9. Schmitz $T$, Korb D, Battie $C$ et al. Neonatal morbidity associated with vaginal delivery of noncephalic second twins. Am J Obstet Gynecol. 2018 Apr;218(4):449.e1-449.e13.

10. Levraut J, Fournier J-P. Jamais la première fois sur le patient! Ann Fr Médecine Urgence. 2012;1-3.

11. Cook DA, Hatala R, Brydges $R$ et al. Technology-enhanced simulation for health professions education: a systematic review and meta-analysis. JAMA. 2011 Sep 7;306(9):978-88.

12. Easter SR, Taouk L, Schulkin J, Robinson JN. Twin vaginal delivery: innovate or abdicate. Am J Obstet Gynecol. 2017;216(5):484-8.e4.

13. Lepage J, Cosson M, Mayeur O, Brieu M, Rubod C. Pedagogical childbirth simulators: utility in obstetrics. Eur J Obstet Gynecol Reprod Biol. 2016 Feb;197:41-7.

14. Axelsdottir I, Ajne G. Short term outcome of the second twin during vaginal delivery is dependent on delivery time interval but not chorionicity. Journal of Obstetrics and Gynaecology, DOI: 10.180/01443615.2018.1514490 
15. Granry JC, Moll MC. Rapport de mission: État de l'art (national et international) en matière de pratiques de simulation dans le domaine de la santé. Dans Cadre Dév Prof Continu DPC Prév Risques Assoc Aux Soins HAS. 2012;

16. Draycott TJ, Crofts JF, Ash JP et al. Improving neonatal outcome through practical shoulder dystocia training. Obstet Gynecol. 2008 Jul;112(1):14-20.

17. Goffman D, Heo H, Pardanani S, Merkatz IR, Bernstein PS. Improving shoulder dystocia management among resident and attending physicians using simulations. Am J Obstet Gynecol. 2008 Sep;199(3):294.e1-5.

18. Crofts JF, Bartlett C, Ellis D, Hunt LP, Fox R, Draycott TJ. Training for shoulder dystocia: a trial of simulation using low-fidelity and high-fidelity mannequins. Obstet Gynecol. 2006 Dec;108(6):1477-85.

19. Deering S, Poggi S, Macedonia C, Gherman R, Satin AJ. Improving resident competency in the management of shoulder dystocia with simulation training. Obstet Gynecol. 2004 Jun;103(6):1224-8.

20. Deering S, Brown J, Hodor J, Satin AJ. Simulation training and resident performance of singleton vaginal breech delivery. Obstet Gynecol. 2006 Jan;107(1):86-9.

21. Birsner ML. A Simulator for Breech Extraction of the Second Twin. Obstet Gynecol. 2018 Jun;131(6):1057-61.

22. Kirkpatrick, D. I. Evaluation of training. In: Craig, \& I Bittel (Eds), Training and development handbook, New York: McGraw-Hill (1967). 
Table 1: Students' feelings and times in maneuvers: comparison between the two sessions (10 students)

\begin{tabular}{|l|l|l|l|}
\hline & Session 1 & Session 2 & $\mathrm{p}$ \\
\hline Anxiety (0-5) & $3.17+/-1.5(1-5)$ & $2.33+/-1.4(0-5)$ & NS \\
\hline Confidence (0-10) & $5+/-0.33(4-6)$ & $6.83+/-1.16(5-8)$ & 0.0003 \\
\hline Fetal foot to vulva (in seconds) & $52.6+/-21.64(25-108)$ & $28.8+/-6.5(17-39)$ & 0.0213 \\
\hline Complete maneuver (in seconds) & $112.2+/-40.84(57-182)$ & $81.8+/-36.5(42-139)$ & NS \\
\hline
\end{tabular}


Table 2: Description of student population (10 students) and subjective assessment of the realism of the method

\begin{tabular}{|c|c|c|c|c|}
\hline Resident & Year of residency & $\begin{array}{l}\text { Experience wih } \\
\text { second twin } \\
\text { delivery }\end{array}$ & $\begin{array}{l}\text { Similar to } \\
\text { reality (among } \\
\text { 5) }\end{array}$ & $\begin{array}{l}\text { Impression of reality } \\
(0-10)\end{array}$ \\
\hline 1 & $2-4$ & Yes & Yes & 8 \\
\hline 2 & $2-4$ & Yes & Yes & 8 \\
\hline 3 & 1 & No & & 7 \\
\hline 4 & 1 & No & & 8 \\
\hline 5 & $2-4$ & No & & 8 \\
\hline 6 & $2-4$ & Yes & intermediary & 8 \\
\hline 7 & $2-4$ & No & & 8 \\
\hline 8 & 1 & No & & 8 \\
\hline 9 & 5 & Yes & Yes & 8 \\
\hline 10 & 5 & Yes & Yes & 7 \\
\hline
\end{tabular}


Summary of Figures and Video

Figure 1: SimMom manikin (LaerdalC)

Figure 2: Amniotic cavity building

Figure 3: Intra-abdominal placement

Figure 4: introduction of the obstetrician's hand and descent of the foot to the vulva

concomitantly with "amniotic" membrane rupture

Figure 5: Intrauterine view of the procedure

Movie 1 and 2: internal podalic version and breech extraction of the second twin by an evaluated resident, intrauterine view 
Figure 1: SimMom manikin (Laerdal@)

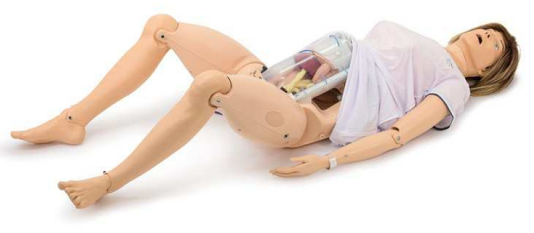


Figure 2: Amniotic cavity building

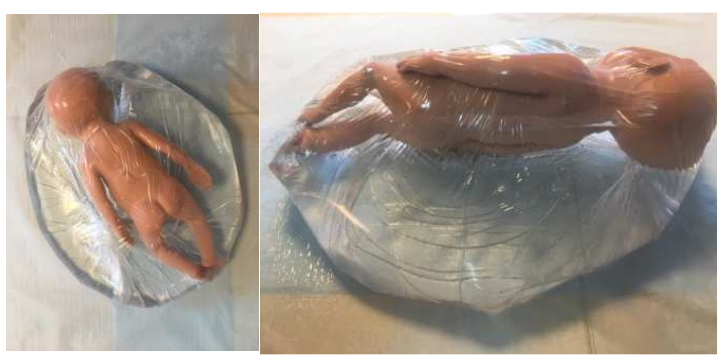


Figure 3: Intra-abdominal placement

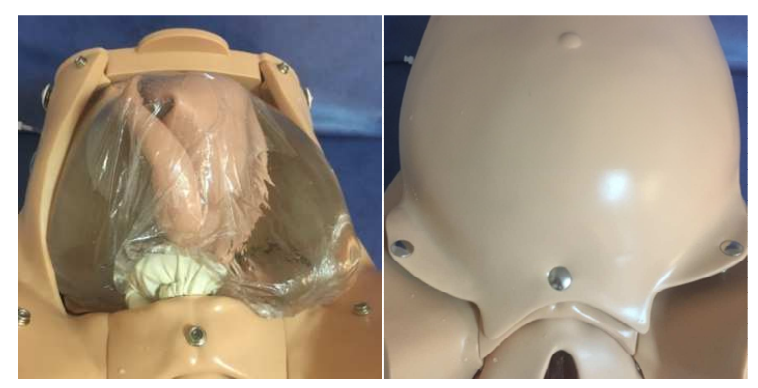


Figure 4: introduction of the obstetrician's hand and descent of the foot to the vulva concomitantly with "amniotic" membrane rupture
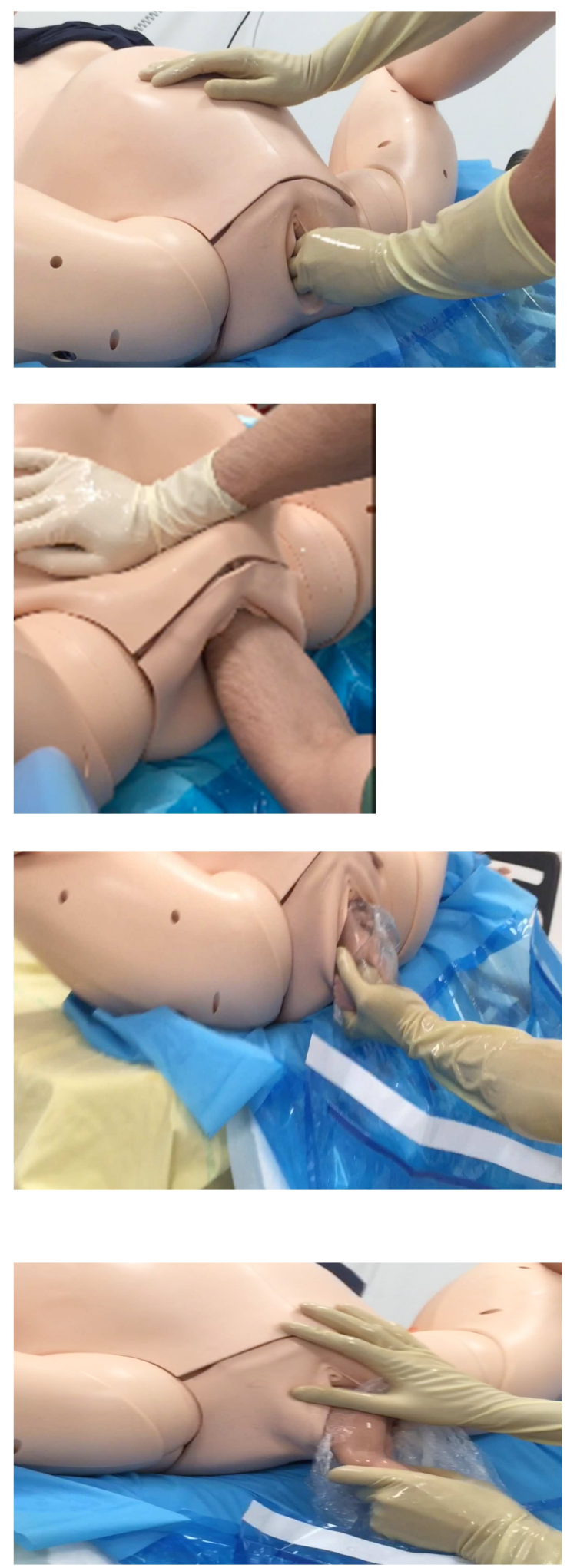
Figure 5: Intrauterine view of the procedure

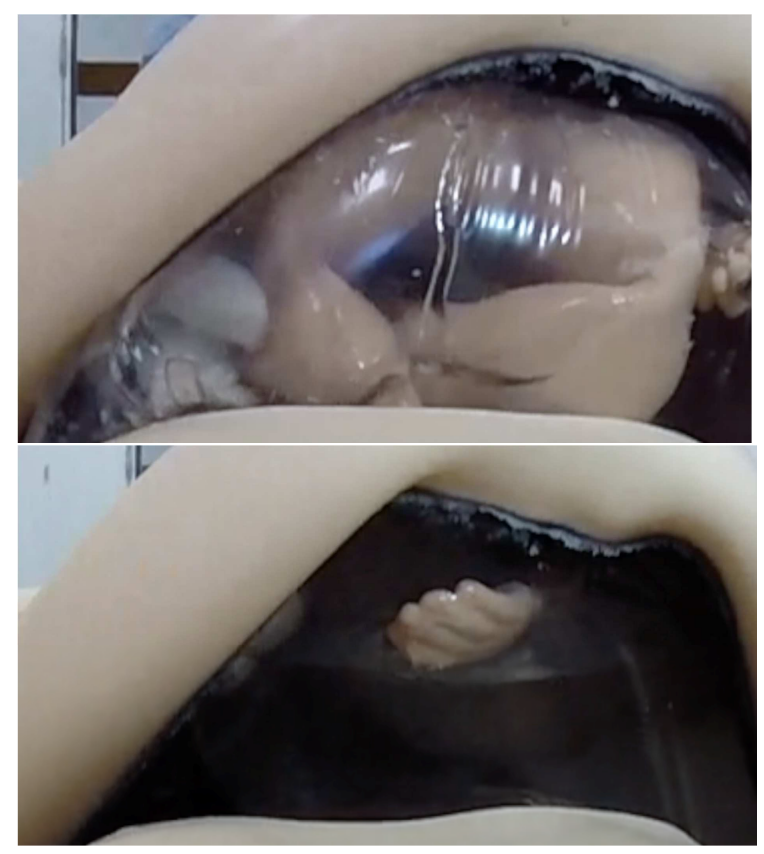


Table 1: Students' feelings and times in maneuvers: comparison between the two sessions (10 students)

\begin{tabular}{|l|l|l|l|}
\hline & Session 1 & Session 2 & $\mathrm{p}$ \\
\hline Anxiety (0-5) & $3.17+/-1.5(1-5)$ & $2.33+/-1.4(0-5)$ & NS \\
\hline Confidence (0-10) & $5+/-0.33(4-6)$ & $6.83+/-1.16(5-8)$ & 0.0003 \\
\hline Fetal foot to vulva (in seconds) & $52.6+/-21.64(25-108)$ & $28.8+/-6.5(17-39)$ & 0.0213 \\
\hline Complete maneuver (in seconds) & $112.2+/-40.84(57-182)$ & $81.8+/-36.5(42-139)$ & NS \\
\hline
\end{tabular}


Table 2: Description of student population (10 students) and subjective assessment of the realism of the method

\begin{tabular}{|c|c|c|c|c|}
\hline Resident & Year of residency & $\begin{array}{l}\text { Experience wih } \\
\text { second twin } \\
\text { delivery }\end{array}$ & $\begin{array}{l}\text { Similar to } \\
\text { reality (among } \\
\text { 5) }\end{array}$ & $\begin{array}{l}\text { Impression of reality } \\
(0-10)\end{array}$ \\
\hline 1 & $2-4$ & Yes & Yes & 8 \\
\hline 2 & $2-4$ & Yes & Yes & 8 \\
\hline 3 & 1 & No & & 7 \\
\hline 4 & 1 & No & & 8 \\
\hline 5 & $2-4$ & No & & 8 \\
\hline 6 & $2-4$ & Yes & intermediary & 8 \\
\hline 7 & $2-4$ & No & & 8 \\
\hline 8 & 1 & No & & 8 \\
\hline 9 & 5 & Yes & Yes & 8 \\
\hline 10 & 5 & Yes & Yes & 7 \\
\hline
\end{tabular}


